\title{
Decision structuring method for the selection of fixed firefighting systems: development and lessons learned from case studies
}

\author{
S. N. Bird ${ }^{1}$, K. Ruikar ${ }^{1}$, L. Bosher ${ }^{1}$, J. Glockling ${ }^{2}$ \\ \& N. M. Bouchlaghem ${ }^{3}$ \\ ${ }^{1}$ Loughborough University, UK \\ ${ }^{2}$ The Fire Protection Association, UK \\ ${ }^{3}$ Nottingham Trent University, $U K$
}

\begin{abstract}
Following a major fire, an historic structure in the UK has been rebuilt to an impressive standard. The fire protection strategy developed as part of the re-build process outlines the six key elements, which all focus on 'life safety' as opposed to 'property protection' ambitions. A 'property protection' approach (more commonly adopted in cases where assets and business continuity are to be protected) usually assures of protection of both life and property, whilst a 'life safety' approach considers a structure sacrificial, once sufficient time has been allowed for safe evacuation. In this case one might expect the protection strategy to place some considerable emphasis upon the need to protect the object itself in the event of another fire. A watermist fixed firefighting system was installed. Such systems are not supported by equivalently rigorous standards, installation and product certifications when compared to the predominant alternative technology; sprinkler systems. The resultant fire risk management and resilience measures were of concern to experts. This case study presents learning opportunities which have potential to inform future risk management strategies and therefore improve decision support.

The aim of this research is to better understand current practice in risk analysis and selection of fixed firefighting systems as part of the fire risk management strategy. Building upon previous work, this paper reports on case studies illustrating aspects of system selection practice and how this experience can contribute to the underpinning knowledge on which to base
\end{abstract}


selection decisions. The paper concludes by considering the likely impact of the development of a Fixed Firefighting System Selection Tool (FFSST).

Keywords: decision support, knowledge management, fixed firefighting system selection, fire, suppression system.

\section{Introduction}

Fixed firefighting systems, combined with appropriate risk assessment and mapping activities are relied upon at a micro scale as risk management measures in support of hazard management and control. Examples of such risk assessment processes include: for buildings; a prescriptive approach: the Department for Communities and Local Government's (DCLG) “The Building Regulations 2010 - Fire Safety, Approved Document B" [1], for buildings; a performance based approach: BSIs code of practice BS 7974 "Application of fire safety engineering principles to the design of buildings" [2]. For machinery BS EN 13478 "Safety of machinery - Fire prevention and protection" [3]. When applied effectively, mitigating measures, which may include fixed firefighting systems, can help to contribute at a macro scale to reduce economic and political vulnerability.

This research is concerned with understanding fixed firefighting system selection practice and seeking ways to optimise outcomes. Previous work $[4,5]$ has determined that there is a need for an Expert System or Decision Support system to be created to assist users in the complex task of assessing hazard and selecting the most suitable means by which to mitigate the risks posed.

Davenport et al. [6] suggest that "knowledge is neither data nor information". Their work then goes on to explore in some detail the process of combining data or information, through use or manipulation, to form knowledge or expertise which may usefully be applied. King [7] reports that knowledge is often described as "justified personal belief". Further that Knowledge Management (KM) allows organisations develop their knowledge bases and make it available to those who may benefit from it. He states that small increases in knowledge utilisation can yield great benefits. As highlighted in the work of Duan [8], the time of subject domain experts (such as those providing advice on fixed firefighting system specification and selection) is sought after and expensive. The scarcity and disparities in the quality and accessibility of supporting information from the perspective of the lay-person seeking to inform themselves, has been highlighted [4]. A considerable amount of the domain knowledge is tacit. Such tacit knowledge, such as custom and practice, tradition, inherited practice, implied values, and prejudgments is acknowledged to be potentially a crucial part of scientific knowledge [9]. So an Expert System, using primarily captured experience based techniques for providing the basis for building automated solutions [10] and "being suited to tasks where expertise, which is the vast body of task-specific knowledge, is transferred from a human to a computer" [11] appears attractive as a proposition in this application, where information and data requires augmenting to render it more useful and accessible to would-be users. 
In pursuing the project aims and objectives (described in section 1.1), it has become apparent that finding usable underpinning data (or knowledge) for some aspects of the work (for example a means to consider the expected likely success rate of one fixed firefighting approach compared to another) can be difficult. A number of examples of fixed firefighting system selection practice of concern have recently come to the attention of the authors. Such "Lessons learned" activities are recognised [12] as being potentially very useful in improving practices and outcomes. However it is also noted in the same work that there are challenges in the areas of the effort required to gain the benefit and subsequent dissemination and use. Care must be taken to ensure that these recent examples are helpful in building the evidence base upon which the design of the firefighting system selection tool will be based. The events are reported as case studies in this paper, accompanied by commentary on the significant findings or lessons and how this can translate in to useful knowledge to be captured in this research.

\subsection{Aim and objectives}

The research aim is to investigate the process of selection of fixed firefighting systems and if warranted to develop a means to assist with the decision making process. Previous work $[4,5]$ has determined that there is a need for the FFSST. It will partially automate the process of fixed firefighting system selection by collecting and analysing relevant data and making recommendations to the user and additionally it should serve as an educational resource by providing information and indirectly by signposting the user to the disparate sources of pre-existing supporting knowledge available to them.

\subsection{Fixed Firefighting System Selection Tool (FFSST)}

The Expert System or Decision Support system referenced above is referred to as a Fixed Firefighting System Selection Tool (FFSST) in the remainder of this paper.

\subsection{Fixed firefighting systems}

The term "Fixed Firefighting System" is in common use in literature as a generic descriptor for any fixed (installed and non-portable) firefighting (with suppression or extinguishing objective) system. Examples of which include the British Standards Institution's (BSI) standard for "components for gas extinguishing systems" (multiple parts) [13], DCLGs "fire safety risk assessment guidance document" [14].

Common causes of fire include electrical equipment malfunction, electrical distribution system malfunction, use of cooking equipment and undertaking hot-works, industrial processes and human actions to name a few [15]. In the built environment as the density, complexity and scale of populations and activity within a building increase, then the potential sources of causes of fire will also increase dramatically in number (electrical equipment and distribution 
systems are a good example of this). So too might the potential scale and consequence of a fire. Fixed firefighting systems tend to be specified as additional fire protection and resilience measures when various perceived risk and consequence thresholds are breached. They may be installed throughout entire buildings or installed to protect local 'objects' (high risk or consequence equipment for example). In the established UK framework (regulations, guidance, custom and practice) for the built environment, fixed firefighting systems are specified or proposed as risk mitigation features under certain circumstances in a number of places. Notably: Approved Document B [1], LPC Design Guide [16], British Standard (BS) 9999 [17], BS 7974 series [2], The Supply of Machinery (Safety) Regulations [18] and the Supply of Machinery (Safety) (Amendment) Regulations [19]. BRE Global's "Sprinkler systems explained: A guide to the sprinkler installation standards and rules" [20] tells us that sprinkler systems (a type of fixed firefighting system) are installed mostly; to meet legislative requirements, or to achieve risk reduction for business resilience purposes.

\section{4 'Life safety' and 'property protection' design objectives}

Fire risk management practice in the UK has evolved to the point where two clearly distinct protection objectives have emerged, commonly referred to in the sector as 'Life safety' or 'Property protection' [5]. The distinction is perhaps most clearly made in BSIs BS 7974 series "Application of fire safety engineering principles to the design of buildings", part 8 , "Property protection, business and mission continuity, and resilience", which states "Frequently, the contents of a building and the work conducted within it are of considerably greater value than the building itself, either intrinsically because of their monetary or historic or cultural value, or indirectly because of the effects of their loss on business or mission continuity, as can be the case for example in computing suites, archives, many industrial plants and also in educational establishments" [21, Section 0.1]. The introductory text continues to confirm that the UK national Building Regulations [22] are intended only to go as far as mandating that life safety considerations be adequately designed for.

Scotland is proposing regulatory changes in its public consultation [23] that acknowledge a difference between the approaches to protection of life and property and question the extent of the remit of the building regulations, such is the strength of the argument that good levels of property protection are also in the interests of society. "...Concerns about fire have traditionally centred on life protection rather than asset protection. A primary objective of the building standards system however is to 'further the achievement of sustainable development.' The sustainability of communities could be served by the protection against both deliberate and accidental fires in buildings such as schools that serve as social assets and components of the local economic network...." [23, Section 2.15.0].

The remainder of this paper outlines the methods used, presents the case studies and key findings, and details the contribution they make to the development of the Fixed Firefighting System Selection Tool. 


\section{Research methods}

The research methods used in preparation of the material reported in this paper have included: literature review (which included regulations, standards, codes of practice and supporting guides), review of related reported case study material (which included fire incident reports, fire engineering design rationales, risk survey reports and independent expert reviewer opinions), consultation and correspondence with experts (who included risk surveyors, insurance industry risk underwriters, fire engineers and fixed firefighting system suppliers). The case studies reported in this paper were used to contribute to the development of the FFSST, as described in subsequent sections of this paper. Owing to commercial sensitivities it has been necessary to preserve a degree of anonymity in some cases.

\section{Case studies}

This section considers case studies which serve to illustrate a variety of influences upon fixed firefighting system selections. The specific case studies were selected because they were contemporaneous to the research, sufficient material was available to make useful deductions and contributions to this research and they span a variety of quite disparate issues all of which may be faced when making a fixed firefighting system selection; thus the issues encountered are germane and highly transferable.

\subsection{Case study 1: active fire protection of an historic structure}

The structure, which was generally considered a unique and highly valued cultural relic and an important part of the nation's heritage, suffered a fire. Partly on account of it not being protected by any active firefighting provision, the fire damage was extensive. Subsequently it has been fully restored at very considerable expense. The Fire Protection Association's (FPA - the industrial sponsor of this research) opinion was sought on the fire engineering design and active fire protection measures proposed to help protect an historic structure. In the ensuing review process, the opportunity arose to review the instructions of the commissioning body (the 'owner' of the structure), the adopted fire engineering design and the design of the active fire protection system. As part of the review, consultations were held with subject matter experts from the Insurance sector. The review concluded that the protection objectives have been incorrectly identified. Considering the impact of the different objectives BSIs Published Document PD 7974-8 states "Although life safety is of utmost importance, a building design which focuses exclusively on life safety might not adequately protect property and business continuity resulting in a building, or plant, with diminished resilience to the effects of fire" [24, Clause 0.2]. Assumptions based upon this incorrect identification of the protection objective 
were carried through to the design of the mitigating features. Finally, variability in the availability, reliability and maintainability of different fixed firefighting systems [5] had not been understood and consequently overlooked.

Key learning outcomes of this case study for this research: identification of protection objectives is complex but critical step. Seeking to ascertain the correct objective should be part of the selection process. There may be opportunities in this research to highlight some of the difficulties commonly encountered in this step. The potential disparity in likely performance of different types of systems should also be considered and highlighted in the system selection process.

\subsection{Case study 2: fire and risk management journal (FRM) article}

An article appeared in a sector trade journal, which is published by the FPA. Typical subscribers to this journal include similar groups of people as have been identified previously in the research as being potentially responsible for making decisions when it comes to firefighting system selection. The article was authored on behalf of the trade association representing a particular type of fixed firefighting system. Whilst the article presents some interesting ideas, subject matter experts at the FPA agreed that aspects of the article appeared unbalanced, which could lead to readers being misinformed. The article exhibited bias in that, for example, no mention of the most obvious alternative choice (sprinkler systems) for the given risk was made. Some of the claims made may be overstating the capability and maturity of the technology. For example by suggesting the technology should be installed to "recognised standards" and then citing "British Standards DD 8458-1: 2010: Fixed fire protection systems. Residential and domestic watermist systems. Code of practice for design and installation and DD 8489-1: 2011: Fixed fire protection systems. Industrial and commercial watermist systems Code of practice". This is misleading because these documents $[25,26]$ are not Standards (the front covers explicitly state "This publication is not to be regarded as a British Standard"). This is important because compliance with appropriate national or international standards is often regarded as a de-facto means to demonstrate fitness for purpose "Where conformity assessment depends on the measurement of the parameters of performance of a product or process, measurements or test results should be traceable to national or international measurement standards" [27, p. 5].

Such material may be a factor contributing to the acceptance of systems in situations such as that highlighted in the previous case study; where, on balance, experts would consider the application to be unsuitable.

Key learning outcomes of this case study for this research: As in the previous case study, the potential disparity in likely performance of different types of systems should be considered and highlighted in the system selection process. The issue also highlights the scarcity of the comparative evidence on system availability, reliability and maintainability required in order to do so. Thus reinforcing the need to develop a means to evaluate the anticipated availability, reliability and maintainability as part of this research. 


\subsection{Case study 3: protection of a high risk piece of industrial equipment}

The FPA was again asked for its opinion on the suitability of fixed firefighting system designs intended to protect a high risk piece of industrial equipment (in this case a computer numerically controlled (CNC) cutting machine). The machine was a high value piece of equipment in itself, but the perhaps more significant factor was the vulnerability of a process of a much higher value upon the equipment. If the machine was damaged or out of service for any considerable period, the commercial consequential losses (such as loss of orders and breach of contracts) could be of the order of tens of millions of pounds.

The equipment incorporated significant quantities of oil, used as a lubricant and coolant. In close proximity to this were potential sources of ignition (heat from the friction arising in the process and sparks from the cutting operation). Experts internal and external to the FPA were consulted and a review of standards and literature was undertaken. The findings were that whilst there is some published guidance it is somewhat short on delivering what it sets out to.

BS EN 13478 - "Safety of machinery - Fire prevention and protection" [28]. This standard invites the user to undertake hazard evaluations as per the methods of EN 1050 [29] and EN 292-1 [28] and cross refers to a number of specific clauses within EN 292-1 [28]. On doing so, if the machine is considered not to be "safe" [28, Figure 4] then it is suggested "the user make improvements, considering the following points in order" [28, clause 5]. However the referenced EN 292-1 [28] is withdrawn, replaced by BS EN ISO 12100-1 "Safety of machinery. Basic concepts, general principles for design. Basic terminology, methodology" [9], which is also withdrawn, replaced by BS EN ISO 12100 "Safety of machinery. General principles for design. Risk assessment and risk reduction" [30]. In the case of BS EN 13218 "Machine tools - Safety Stationary grinding machines" its stated scope is to "...specify the technical safety requirements and/or protective measures to be adopted by persons undertaking the design, construction and supply of stationary grinding machines ...". At clause 5.8, "Measures against fire and explosion hazards", it states “...Such measures may include: Fire extinguishing devices, Pressure relief devices ...". The use of the word 'may' (instead of 'shall') renders it ambiguous as to whether fire extinguishing devices are required or not.

Key learning outcomes of this case study for this research: Both sets of cited guidance contain significant areas of subjectivity and inconsistency; with further difficulties in application being encountered due to obsolescence of referenced documents. These problems were encountered in areas that could make a critical difference to how and to what design fire protection measures were implemented and are considered a real problem to practitioners seeking to apply the guidance. FPA are aware of instances when the design of fixed firefighting systems has been compromised and it is considered that better guidance could have helped to avoid such compromises. At this time, no more definitive standardised guidance on the protection of such risks was identified, therefore it is considered there is a gap in the base of underpinning knowledge relating to essential principles of the 
design of fixed firefighting protection for high risk and consequence objects such as the one considered in this case.

\section{Implications for the FFSST development}

The positioning of the learning outcomes from the case studies is within the development of the FFSST is illustrated in Figure 1.

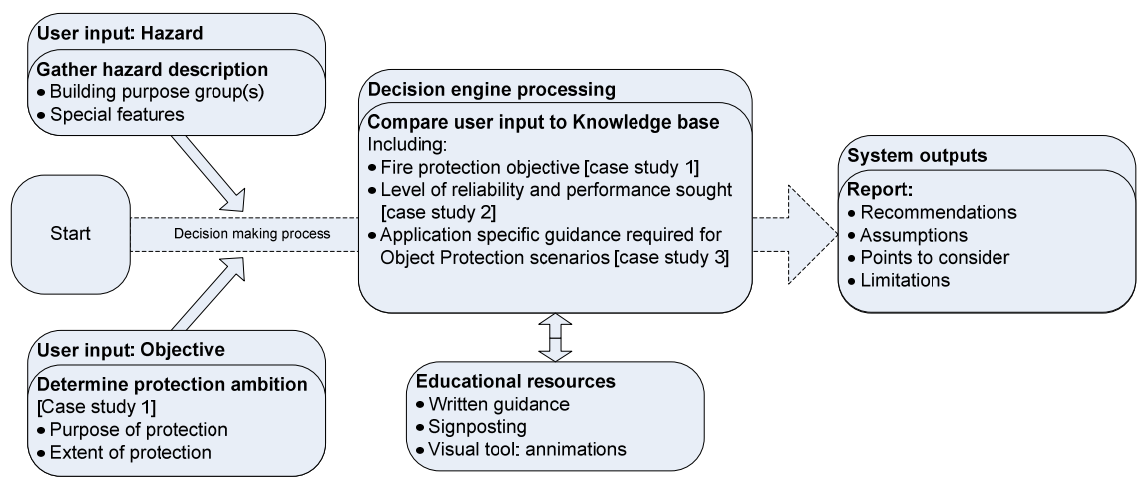

Figure 1: Overview of FFSST architecture incorporating case study lessons.

It is intended that improvements in the observed position from the three case studies can be made in the following ways: Seeking to ascertain the correct fire protection objective is a critical (but complex) step and should form part of the fixed firefighting system selection process. It will be possible to construct the FFSST such that early in the process, the tool asks the user what the protection objective is. It will be necessary to accompany this question with education material giving advice on the differences and importance of this point to outcomes. This could be accomplished by explanatory text, illustrations and possibly even animations.

The absence of and need for performance (reliability) data relating to different types of firefighting systems, or alternative to this, an adequate means to anticipate what the approximate level of reliability might be is considered a more complex problem and will be the subject of further work in this research.

When considering knowledge gaps in guidance for the design of fire protection for high risk individual pieces of equipment, it is proposed that incremental improvements can be made by filling some of the gaps identified in section 3.3. For example the disjointed structure of the existing information (in the referenced British and European Standards) could be improved by consolidating and enhancing the advice offered and making the advice accessible via the FFSST. Again, further work will be required to develop and structure this portion of 'knowledge' within the tool. A starting point would be to consider the overarching intent of the British and European Standards, graphically represented in figure 2 . 


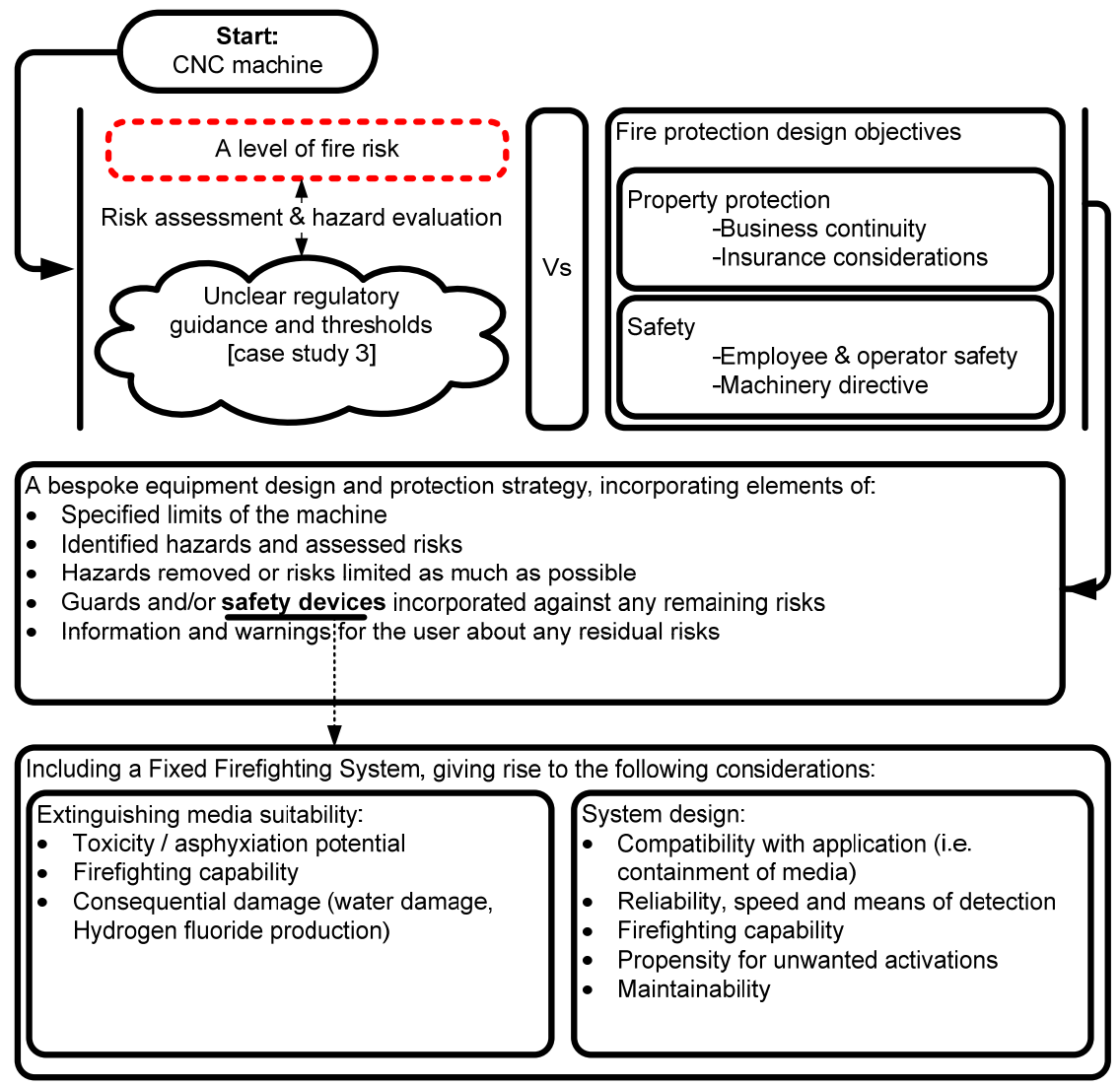

Figure 2: Possible FFSST implementation model for object protection scenarios.

\section{Conclusions}

The case studies reported in this paper illustrate the importance of correctly identifying fire protection objectives in order for the outcome of the subsequent fire protection measures design process to stand the best chance of delivering the most suitable solution. They also highlight examples of the potential misinformation being propagated by some factions of the fire protection industry, the incomplete support afforded to users of fixed firefighting systems in the form of the relevant European regulations and associated guidance and the lack of useable expected performance data. Areas that are particularly problematic are risk assessment and lack of consistent methods of risk mapping, giving rise to inconsistent levels of risk management, hazard prevention, management and control. However, in identifying these problems and sources of literature, and through the continuation of this research, using the methods 
outlined in this paper and previously reported [4] and [5], it will be possible to systematically derive improvements in the areas of identified shortcomings, through filling knowledge gaps and enshrining the knowledge in the decision support system and/or through creating educational resources (accessed through the decision support system) in order to tackle frequently misunderstood aspects. King notes that even small increases in knowledge utilisation will yield great benefits [7]. This work has the potential to deliver considerable increased in knowledge.

The next steps in the research will be to: complete the development of a methodology to consider the likely availability, reliability and maintainability of different types of fixed firefighting systems, to complete the development of the first release of the FFSST and to evaluate its performance.

These steps will help to fulfil the objectives of the research; to evidence the need for and deliver a decision support and educational tool (the proposed FFSST) intended to improve levels of safety and security. Ultimately this is to help achieve improved levels of business continuity and resilience and at the macro scale contributing to reduced political and economic vulnerability.

\section{References}

[1] DCLG, The building regulations 2010 fire safety approved document $B$. 2010, London, UK: NBS for the Department of Communities and Local Government.

[2] BSI, BS 7974: Application of fire safety engineering principles to the design of buildings - Code of practice. 2001, BSI: London, UK.

[3] BSI, BS EN 13478 (+ A1) Safety of machinery - Fire prevention and protection. 2008, London, UK: BSI Group.

[4] Bird, S.N., et al., Decision problem structuring method for the specification and selection of active fire protection systems, in Innovation in Architecture, Engineering and Construction (AEC). 2012: Sao Paulo, Brazil.

[5] Bird, S.N., et al., Development of a Fixed Firefighting System Selection Tool for Improved Outcomes. ITcon 2013. 18: p. 353-371.

[6] Davenport, T.H., et al., Working knowledge: how organizations manage what they know. Ubiquity, 2000. 2000 (August): p. 2-es.

[7] King, W., Knowledge Management and Organizational Learning, in Knowledge Management and Organizational Learning, W.R. King, Editor. 2009, Springer US. p. 3-13.

[8] Duan, Y., Web-based expert systems: benefits and challenges. INFORMATION \& MANAGEMENT, 2005. 42(6): p. 799-811.

[9] Polanyi, M. and A.K. Sen, The Tacit Dimension. 2009, London University of Chicago Press.

[10] Nguyen, H.H., et al., A comparison of automation techniques for optimization of compressor scheduling. Advances in Engineering Software, 2008. 39(3): p. 178-188. 
[11] Liao, S.-H., Expert system methodologies and applications-a decade review from 1995 to 2004. Expert Systems with Applications 28 (2005) 93-103, 2005. 28(1): p. 93-103.

[12] Paranagamage, P., et al., Lessons learned practices in the UK construction sector: current practice and proposed improvements. Engineering Project Organization Journal, 2012. 2(4): p. 216-230.

[13] BSI, BS EN 12094 - Fixed firefighting systems - Components for gas extinguishing systems (multiple parts). 2003, London, UK: British Standards Institute.

[14] DGCL, Fire safety risk assessment: Educational premises (Fire Safety Employers Guide). 2006, London, UK: Department for Communities and Local Government.

[15] DCLG, Fire statistics Great Britain - 2011 to 2012. 2012, Department for Communities and Local Government: London, UK.

[16] The Fire Protection Association, LPC Design Guide for the Fire Protection of Buildings. 2000 ed. 1999, Moreton-in-Marsh, UK: The Fire Protection Association and ABI.

[17] BSI, BS 9999 Code of practice for fire safety in the design, management and use of buildings. Vol. 1st. 2008, London, UK: BSI Group.

[18] HMSO, The Supply of Machinery (Safety) Regulations. 2008, England and Wales: London.

[19] HMSO, Supply of Machinery (Safety) (Amendment) Regulations. 2011, England and Wales: London.

[20] BRE Global, Sprinkler systems explained. A guide to the sprinkler installation standards and rules. Vol. 1st. 2009, Watford, UK: BRE IHS Press.

[21] BSI, Application of fire safety engineering principles to the design of buildings, in Part 8: Property protection, business and mission continuity, and resilience. 2012, BSI: London, UK.

[22] HMSO, The Building Regulations No. 2214. 2010, England and Wales: London.

[23] The Scottish Government. Review of the Building (Scotland) Regulations 2004: Technical Handbooks (Non Domestic) - Section 2 (Fire). 2012 Wednesday 19th September 2012 [cited 2013 14th October]; Available from: http://www.scotland.gov.uk/Publications/2012/09/4547/2.

[24] BSI, PD 7974-8 Application of fire safety engineering principles to the design of buildings, in Part 8: Property protection, business and mission continuity, and resilience (Sub-system 4). 2012, BSI: London, UK.

[25] BSI, DD 8489-1 Fixed fire protection systems - Industrial and commercial watermist systems - Part 1: Code of practice for design and installation. 2011, London, UK: British Standards Institution.

[26] BSI, DD 8458-1 Fixed fire protection systems. Residential and domestic watermist systems. Code of practice for design and installation. 2010, London, UK: British Standards Institution.

[27] Department for Business, I.S., Conformity Assessment and Accreditation policy in the UK. 2012. 
[28] BSI, BS EN 292-1 Safety of machinery - Basic concepts, general principles for design - Part 1: Basic terminology, methodology 1991, London, UK: BSI Group.

[29] BSI, BS EN 1050 - Safety of machinery - Principles for risk assessment. 1997, London, UK: BSI Group.

[30] BSI, BS EN ISO 12100 - Safety of machinery - General principles for design - Risk assessment and risk reduction. 2010, London, UK: BSI Group. 